\title{
Ethics of Clinical Supervision: An International Lens
}

\author{
Carol A. Falender ${ }^{\mathrm{a}, \mathrm{b}}{ }^{*}$ \\ ${ }^{a}$ Pepperdine University, Los Angeles, USA \\ ${ }^{b}$ University of California, Los Angeles, USA \\ * Corresponding author. E-mail: cfalender@gmail.com
}

Background. Although widely acknowledged as a distinct professional practice, clinical supervision has not consistently been a component of graduate training in psychology, and has not achieved recognition commensurate with its importance to the field in the United States or internationally. Although competence in supervision had been inferred, multiple international studies reveal high frequencies of unethical, inadequate, and harmful supervision. Implicit in clinical supervision is ethical acumen, practice, modeling, teaching, and adherence to multiple ethical principles and codes. Specifically, this role calls for respect, integrity, doing no harm, competence, confidentiality, and not entering multiple relationships that may do harm.

Objective. The objective of the current article is to describe the essential components of ethical clinical supervision and training, ethical imperatives for both supervisor and supervisee, and aspects of training and supervision that ensure protection of the client. A framework of enlightened globalization harmonizes rules and ideals of the profession with cultural diversity and provides both a structure and guidance for supervisors and supervisees.

Results. We analyze the ethical development of supervisees which occurs through a complex process of integration of personal values and ethical positions with professional ethics; through an intentional, systematic process; and through supervision, to enhance their metacompetence (i.e., knowing what one knows and doesn't know).

Conclusion. Through a review of the strategic literature, we define current international and cultural perspectives on ethical practice and training, outline critical ethical issues, and provide strategies for effective and ethical clinical supervision, including an informed consent document and a supervision contract.

Keywords: clinical supervision; ethics; ethical clinical supervision; supervision; international supervision 


\section{Introduction}

Clinical supervision is internationally acknowledged to be the most important influence on psychologists' clinical practice (Orlinsky, Ronnestad, \& the Collaborative Research Network of the Society for Psychotherapy Research, 2005). It is the main means of instilling ethical knowledge, skills, and attitudes in a supervisee during the training process. Supervisors thus bear significant responsibility to their supervisees and clients; their highest responsibilities are to protect the client and public; to ensure no unsuitable supervisees enter the profession; and to support and advance the development, competence, and ethical practice of their supervisees.

A sea change in supervisory practice, and the magnitude of the change toward a competency-based framework, have caught many supervisors by surprise (Gonsalvez \& Calvert, 2014). Specific ethical supervisory practices (Barnett \& Molson, 2014; Falender \& Shafranske, 2014, in press; Pettifor, McCarron, Schoepp, Stark, \& Stewart, 2011) have been described. However, clinical supervision is generally not the subject of formal coursework during a psychologist's training. Supervisors who have no formal training may supervise the same way they were supervised, through a process of osmosis or absorption of the practices of their supervisors. This process is fraught with peril for both ethics and practice, since it is increasingly clear that a substantial quotient of inadequate or harmful supervision occurs in multiple international locales. Furthermore, low value may be attached to the importance of clinical supervision by individuals who lack formal supervisory training (Rings, Genuchi, Hall, Angelo, \& Cornish, 2009), and by training directors who even urge that it be eliminated from the training process (Stedman, Schoenfeld, \& O'Donnell, 2013).

When supervisory training is offered, it may be through a psychotherapy-based model, which may not be systematic or include all the multiple components and dimensions of supervision (Falender, 2018; Falender \& Shafranske, 2010). Specifically, psychotherapy models may not systematically and directly address the supervisee's emotional reactivity, multicultural diversity, or legal and ethical aspects, for example. Ethical clinical supervision requires competence in all aspects of client assessment, intervention, and outcomes through multicultural frameworks, as well as competence in the provision of effective supervision in these. All aspects of local ethical codes and standards must be known and upheld, including informed consent; competence; oversight and monitoring; reflection and caution in multiple relationships; modeling reflective ethical behavior; identifying ethical issues in a positive framework; and problem-solving.

Contrary to the assumption that all supervisors are competent, supervisees report significant levels of less than adequate supervision. Consensus exists across disciplines and international venues about what constitutes effective versus inadequate or harmful supervision. Harmful supervision was defined as "the supervisor's actions or inactions resulting in psychological, emotional, or physical harm to the supervisee" (Ellis et al., 2014, p. 7). Inadequate supervision may not be harmful, but poses significant risk, as it may be characterized by failure to meet legal and ethical standards (e.g., competency, time, consistency, attention); supervisory disinterest; lack of investment; failure to provide accurate and timely feedback and evaluation of supervisee competencies; or disrespect or disregard of supervisee input. 
Studies in multiple countries also identify the incidence of inadequate and harmful supervisory practice: in the United States, Ellis et al. $(2014,2017)$ and Ladany, Mori \& Mehr (2013); in Ireland, Ellis, Creaner, Hutman, \& Timulak (2015); in South Africa, Hendricks \& Cartwright (2017); in Australia, Lovell (2007); and in Korea, Bang \& Goodyear (2014). Ladany and colleagues (Ladany, Lehrman-Waterman, Molinaro, \& Wolgast, 1999) and studies conducted by our Pepperdine University research group (Hansell, 2018; Wall, 2009) found supervisees' perception of ethical misconduct by their supervisors was associated with lower alliance ratings by supervisees. When supervisors allow use of treatment methods of which they have limited knowledge, or schedule supervision on an as-needed basis rather than providing regular supervision sessions, the consequences affect the alliance as well as the integrity of supervision, and ultimately the quality of client care. Both inadequate and harmful supervision constitute ethical breaches with significant impact upon both client and supervisee wellbeing.

Other studies identify ethical errors that supervisees perceive their supervisors to have committed. In a study of 151 beginning- to intern-level supervisees, $51 \%$ reported at least one ethical violation by their supervisors. Among the most frequently reported infractions were failure to provide supervisees with adequate performance evaluations; violating supervisee confidentiality; not working with alternative perspectives; disregard for session boundaries; and disrespectful behavior (Ladany, Lehrman-Waterman, Molinaro, \& Wolgast, 1999). These findings are generally replicated by Wall (2009).

\section{Method}

To enhance ethical clinical supervision, a number of perspectives and objectives are required. First, general parameters of ethical supervision will be discussed. Next, international guidelines for clinical supervision and the ethics of clinical supervision will be listed, showing the agreement among them on the central concepts that distinguish supervision from clinical practice, followed by identifying the specific ethical standards and their importance in clinical supervision internationally. Cultural variants of ethical codes and particular aspects of ethics will be described. Next we'll discuss the trajectory of supervisee ethical development. Finally, a summary discussion of ethical competence for supervisors is provided.

\section{Results}

\section{Parameters of Ethical Clinical Supervision}

There is significant international agreement on the ethical aspects of clinical supervision. The following are some of the premises:

1. There is a firm line between clinical supervision and personal psychotherapy. That is, an individual who is providing clinical supervision holds power over the future of the supervisee. It is not appropriate for such an individual, the supervisor, to also conduct therapy with that supervisee. This premise is specified in multiple ethical codes internationally.

2. Respect for the Dignity of Persons and Peoples 
3. Competence. Supervisors must be competent both in the clinical services the supervisee renders and in the practice of clinical supervision. If either the clinical presentation or the supervision are beyond the competence of the supervisor, the supervisor is responsible for determining a course of action to ensure adequate supervision. Proceeding ethically is essential. This includes beneficence and doing no harm.

4. Informed consent. An informed consent agreement should cover expectations for the supervisee and the supervisory process; contingencies in case of emergencies or cancellations; limits to the confidentiality of supervisee disclosures; jurisdictional legal and reporting regulations; recordkeeping; and specific information relevant to the entire setting. A written supervision contract formalizes the aspects and expectations for performance and successful completion of the supervisory sequence.

5. Boundaries and multiple relationships. Establishment of clear boundaries to allow both supervisor and supervisee to maintain objectivity is imperative. As described in a later section, some aspects of boundaries may be culturally variable (e.g., gift giving). However, given the power of the supervisor and the vulnerability of the supervisee, clarity of boundaries and a thoughtful approach to boundary crossings is essential. For example, if a supervisor had lunch frequently with one supervisee and never with the others, what impact might that have on a) the supervisee's behavior and judgments, and b) on the other supervisees in the setting?

6. Evaluation. Supervisors are responsible for providing ongoing feedback, monitoring of client care and outcomes, and ensuring the progressive growth of the supervisee's competence. Feedback should be normative, ongoing, and frequent, ideally linked to behavior observed, or if that is not possible, through supervisee report. Direct observation is highly desirable to address the question of metacompetence, or whether the supervisee knows what he/she does not know or observe.

\section{International Guidelines for Clinical Supervision and the Ethics of Clinical Supervision}

Multiple countries and jurisdictions have developed guidelines for clinical supervision and/or the ethics of clinical supervision. Among those are: the American Psychological Association's Guidelines for Clinical Supervision of Health Service Psychologists (2014, 2015); the European Federation of Psychologists' Associations' (EFPA) Ethical Guidelines for Psychologists in the Role of Trainers, Supervisors and Teachers of Psychologists (2019); the Association of State and Provincial Psychology Boards Supervision Guidelines for Education and Training leading to Licensure as a Health Service Provider (2015); the Psychology Board of Australia Guidelines for Supervisors and Supervision Training Providers (2013); and the New Zealand Psychologists Board Guidelines on Supervision (2007). The Universal Declaration of Ethical Principles for Psychologists also provides a common moral framework and ethical principles for psychologists (International Union of Psychological Science, 2008). 
There is a confluence of competencies (knowledge, skills, and attitudes) across many international venues, which share the following themes: 1) knowledge of the profession and areas under supervision; 2) competence assessment; 3 ) multicultural diversity; 4) reflective practice; 5) evaluation; 6) ethical and legal standards and professionalism; 7) supervisory relationship processes, including reactivity, strains, and ruptures; 8) supervision competence assessment, feedback, and evaluation; 9) infusion of diversity and a worldwide perspective of all participants; and 10) modeling reflective process and self-awareness (adapted from Falender \& Shafranske, 2004; Watkins, 2013).

An analysis of the ethics codes from 24 countries revealed significant agreement on many ethical principles and codes critical to clinical supervision. Sixtyeight percent of nations included guidance about multiple relationships in their code; $68 \%$, the aspirational principle of competence; $79 \%$, informed consent for therapy; and 95\%, maintaining confidentiality. Overall, ten specific standards were presented in common, occurring in more than $75 \%$ of the codes (Leach and Hardin, 1997). At least 11 more countries have substantial ethical standards relating to supervision in their general code, including the Russian Psychological Society Code of Ethics (2012). Significant cultural issues arise internationally concerning the overlap between professional and nonprofessional relationships, the normative values of interdependence of community and family, and individualistic versus collectivist values.

\section{Specific Ethical Standards and Their Importance in Supervision Internationally}

To frame the ethical issues in the training process and supervision, the following section considers several ethical aspects through an international lens, with a specific focus on their application to the supervisory process.

\section{Boundaries and Dual and Multiple Relationships}

There has been increasing attention directed to multiple relationships, including the inevitability of some, and the significant impact of culture upon the ethical standards. Some ethical codes state that not all multiple relationships are unethical, specifically in cases when they would not "reasonably be expected to cause impairment or risk exploitation or harm" (APA, 2017, 3.05 (a)). In some cultural contexts, avoiding dual relationships is actually considered disrespectful and insensitive. In the United States, Zur (2017) advocates a loosening of the standard, suggesting that multiple relationships may be an asset and enhance therapeutic acuity and outcome. Generally, autonomy and self-determination, community and family interdependence, and connections between persons are highly valued in non-Western societies (Pettifor \& Ferrero, 2012).

In clinical supervision, the power differential is significant, since the supervisor serves as a gatekeeper, determining whether the supervisee may move into independent practice. The potential for strain and rupture in the supervisory relationship is great when the supervisor and supervisee slide into a quasi-friendship relationship that reverts, by necessity, to an evaluative one. Furthermore, due to the power differential, the supervisee generally cannot refuse a supervisor's request, 
even if the request is something that the supervisee is not comfortable with. Many ethics codes suggest the multiple relationships of supervision by a spouse or other family members are inherently problematic, and thus prohibited.

Attentiveness to the potential for abuse of power, exploitation, and conflicts of interest are a supervisory responsibility. However, high value may be attached to seeking out therapy and supervision with someone known personally and respected due to the interdependence of community and family. Avoidance of dual relationships is sometimes actually viewed as disrespectful and insensitive (Deng et al., 2016). These issues may introduce ethical and worldview conflicts among supervisors, supervisees, and clients. Thomas (2014) concluded that it is difficult, and even undesirable, to have no connections or multiple relationships with supervisees, and that a thoughtful process is required in supervisor-supervisee relationships as well as in therapist-client ones. Ethical problem-solving is an effective tool (Gottlieb, Robinson, \& Younggren, 2007).

\section{Competence}

Clinical supervision is broadly viewed as a means for establishing and ensuring the competence of the supervisee. Supervisors in many countries are required to receive supervision competency training. In several jurisdictions, receiving supervision is a requirement throughout the professional trajectory (i.e., U.K. and Australia), and in Australia, the competence of supervisors is formally evaluated at intervals.

An essential aspect of enhancing and ensuring a psychologist's competence is feedback from the supervisor to the supervisee. That is, when supervisors perceive problems in the knowledge, skills, and/or attitudes of their supervisees, it is imperative they provide feedback, monitor the supervisee's practice, and ensure the protection of the client. Furthermore, supervisors bear responsibility for competence in all the areas they supervise. Particular aspects of supervisory practice such as feedback may not be culturally syntonic: For example, feedback is essential to the Western style of supervision and competency tracking-but the feedback may result in a loss of face and be viewed as disrespectful, and thus be difficult to give in some non-Western cultures. However, there is universal agreement on the necessity for competence, as shown, for example, by interest in the document Competencies Benchmarks (Fouad et al., 2009), which has been translated in Taiwan and China.

However, the ability of the supervisee to give feedback and collaborate with the supervisor is also very important. This requires a trusting relationship. A relevant concept for achieving this is enlightened globalization (Kim \& Park, 2007), as contrasted with unilateral globalization. Under enlightened globalization, supervisory practice and guidelines should strive to serve the interests of all peoples and persons, whereas unilateral globalization is a modern form of oppressive colonialism that results in promoting the advantage of some over others.

In supervision, one end of the spectrum is the unilateral imposition of behavioral expectations ("rules") as equally valid to persons of all cultures. Ostensibly a supervisor using this method would not be open to feedback or perspectives from the supervisee. At the other end of this spectrum is an enlightened approach that, first and foremost, considers the ideals and ethical principles of the profession, and responds to cultural differences with an openness and welcoming of cultural dis- 
cussion and framing (Pettifor, Sinclair, \& Falender, 2014). One result of unilateral globalization in supervision is the potential for alliance ruptures and client harm, when supervisees do not feel they have the power to address perceived ethical or practice infractions and multicultural aspects. Multicultural discussions generally don't occur in clinical supervision. Multicultural competence requires consideration and discussion of the intersectional identities of the client, supervisee/therapist, and supervisor, their resultant worldviews, and the impact of all of those on the therapeutic relationship, assessment, and treatment (Falender, Shafranske, \& Falicov, 2014). There are resources which provide multicultural guidelines, such as An Ecological Approach to Context, Identity, and Intersectionality (APA, 2017).

These factors are of critical importance, and even more so in light of the halflife of psychological knowledge, i.e., the time it would take, in the absence of new learning, to master approximately half the knowledge necessary for the profession, which is generally a function of the development of new knowledge (Neimeyer, Taylor, Rozensky, \& Cox, 2014). Average half-lives of knowledge in professional psychology are projected to decrease within the next decade from nearly nine years to just over seven years. The range of half-lives is currently from 19 years (psychoanalytic psychology) to 4.36 (clinical neuropsychology) to 3.63 (psychopharmacology).

Supervisory competence has been assumed, but may not be the case, especially when the supervisor has received no formal training in supervision per se. Supervisory self-assessment is an important tool for the supervisor, so that he or she can model and identify areas where additional training is necessary (Falender et al., 2016; derived from the American Psychological Association Guidelines for Clinical Supervision, APA, 2014, 2015).

\section{Confidentiality}

Since the time of Hippocrates, confidentiality has been considered a cornerstone of ethics in patient care. However, concepts of autonomy and individuality, collectivism, and family interdependence are relevant to such considerations. Clarity about the confidentiality of personal disclosures by supervisees is limited. Supervisees often assume confidentiality, but the supervisory responsibilities of protection for the client, and abiding by institutional, ethical, and legal regulations, as well as duty to educational institutions, actually limit confidentiality (Falender \& Shafranske, in press).

Confidentiality issues in therapy may create ethical dilemmas in some countries. Exceptions to confidentiality - mandatory reporting laws for child abuse, for example - exist in some jurisdictions, although some are voluntary (Liu \& Vaughn, 2019). Issues of privacy, family responsibility and loyalty, worldviews, and cultural factors all intersect with confidentiality exceptions and may be additional elephants in the supervision and therapy rooms (Pettifor et al., 2014).

\section{Informed Consent}

Articulated in many ethics codes and supervisory guidelines is the necessity for informed consent and clarity of expectations for clinical supervision. There is also the ethical imperative that clients have informed consent that their therapist is a 
supervisee under supervision, and that all client sessions and data will be disclosed to and directed by the supervisor who holds responsibility for the clinical work. If audio or video recording is to occur (an increasingly common practice), informed consent from the client must also be obtained, with clarity about the use, storage, confidentiality, and process for erasure of the recordings.

Use of a written supervision contract such as the one outlined in the American Psychological Association Guidelines (2014) is useful. It may include:

a. Content, method, and context of supervision-logistics, roles, and processes.

b. Clarity about the highest duties of the supervisor: protection of the client(s) and gatekeeping for the profession, while enhancing supervisee development and competence.

c. Roles and expectations of the supervisee and the supervisor, supervisee goals and tasks.

d. Criteria for successful completion and processes of evaluation.

e. Processes and procedures when the supervisee does not meet performance criteria, or reference to such if they exist in other documents.

f. Expectations for supervisee preparation for supervision sessions (e.g., video review, case notes, agenda preparation) and informing the supervisor of clinical work and risk situations.

g. Limits of confidentiality of supervisee disclosures, behavior necessary to meet ethical and legal requirements for client/patient protection, and methods of communicating with training programs regarding supervisee performance.

h. Expectations for supervisee disclosures, including personal factors and emotional reactivity, or countertransference and worldviews.

i. Legal and ethical parameters and compliance, such as informed consent, multiple relationships, limits of confidentiality, duty to protect and warn, and procedures for emergency situations.

j. Processes for ethical problem-solving in the case of ethical dilemmas (e.g., boundaries, multiple relationships) (Adapted from APA, 2014, p. 24-25).

\section{Supervisee Development and Ethical Acculturation}

Understanding supervisee socialization and acculturation into ethical practice is essential. In some ethics acculturation models (Handelsman et al., 2005; Knapp, Vandecreek, \& Fingerhut, 2017)), supervisors are cognizant of how supervisees integrate their own personal ethics with professional ones. The four resultant quadrants of ethical behavior are: 1) marginalized, which is characterized by low personal and professional standards, and therefore potentially exploitative; 2) separated, which involves having adopted professional standards but lacking compassion, which makes the standards potentially rigid or legalistic; 3) assimilated, i.e., personal compassion is not restrained by professional ethics so there exists potential for overinvolvement; and 4) integrated with professionally informed practice and modulated by personal compassion. One supervisory task is to move the su- 
pervisee towards integrated ethical behavior, the highest level of development, and to monitor supervisee maintenance of objectivity in their clinical work.

Another supervisory responsibility for ethical practice is to be aware of metacompetence, both personally and for the supervisee. Metacompetence refers to awareness of what one knows and what one does not know. The latter is challenging to define, as we do not know what we do not know (Falender \& Shafranske, 2007). A possible consequence of problems with a supervisee's metacompetence is he or she not recognizing their own behavior as deviating from their usual patterns, which may result in nondisclosure to their supervisor of their own countertransference or of clinical errors (although there are other reasons for nondisclosure, including an insecure supervisory relationship) (Ladany, Hill, Corbett, \& Nutt, 1996; Wall, 2009).

A supervisor's total reliance on supervisee reporting or self-disclosure of what transpired in a clinical session is a significant problem. Supervisees may not identify clinically significant aspects of the client session or process, the ethical issues that arise, or general facilitators or impediments to treatment. New regulations for accreditation (APA CoA, 2018) in the United States directly address this by requiring each supervisor to conduct direct observation - live, video, or audio - to more effectively provide training and guide client care.

\section{Discussion}

\section{Ethical and Effective Supervision}

Recognition that supervision is a distinct professional competence that requires training is an essential first step. Supervisors hold responsibility for both client care and for their supervisees, and for understanding and integrating the worldviews and belief structures of the client(s), supervisees, and themselves. The supervisor models ethical behavior, thus providing a hidden curriculum that is supported by multiculturally competent ethical practice. Supervisors should self-assess their own supervisory competence. Generally, the supervisor should be competent in the areas under his/her supervision, including understanding multicultural factors, modeling metacompetence, or considering what one does not know, and creating an environment in which communication and the supervisory and therapeutic relationships are facilitated. Acknowledging the limits of a supervisor's own competence and requisite the ethical steps to address those limits is critical.

The supervisor provides informed consent to the supervisee regarding the multiple aspects of the supervisory relationship, expectations, and evaluation; this is codified in a supervision contract. Establishment of the supervisory relationship requires a respectful process and collaboration in the competence assessment of the supervisee, as well as in the setting of goals and tasks. An emotional bond is developed, inviting trust, supervisee self-reflection and self-assessment, and reinforcing metacompetence. Developing an environment that enhances communication supports a supervisory working alliance, while establishing and supporting clear boundaries that are articulated for the specific setting.

The supervisor's reflective process allows for monitoring and addressing the impact of relational dynamics and parallel processes, as well as the supervisee's emotional responses, reactivity, and countertransference, thus ensuring that the focus remains on the impact on the client and does not cross a line into personal 
psychotherapy with the supervisee. Ethical problem solving is an effective tool for assisting supervisees in identifying and determining action when supervisory and clinical dilemmas arise. Supervisors will find that supervisees' ethics training is focused primarily on risk avoidance and knowledge, sometimes rote knowledge, of the ethics code, but does not necessarily identify ethical dilemmas within the expanse of the clinical presentation and setting. Supervisors must model positive ethics, ensuring that supervisees understand and promote the highest ethical conduct and aspirational principles.

The supervisors' ethical knowledge, skills, attitudes, and competence should be strong, modeling adherence to ethical principles and codes, and reflective practice. Supervisors are also challenged to identify ethical aspects of clinical presentations and supervisee-client interactions, and to provide a respectful process that attends to the various requisite competencies needed to ensure that supervisees learn and provide the best care, protecting and enhancing the outcome for the clients they serve.

\section{References}

American Psychological Association. (2018). Standards of accreditation: Implementing Procedures. Washington, D.C.: Commission on Accreditation. Retrieved from https://www.apa.org/ed/accreditation/about/policies/implementing-guidelines.pdf

American Psychological Association. (2017). Ethical principles of psychologists and code of conduct (2002, Amended June 1, 2010 and January 1, 2017). Retrieved from http://www.apa.org/ethics/code/ethics-code-2017.pdf

American Psychological Association. (2017). Multicultural Guidelines: An Ecological Approach to Context, Identity, and Intersectionality. Retrieved from: http://www.apa.org/about/policy/multicultural-guidelines.pdf

American Psychological Association. (2015). Guidelines for clinical supervision in health service psychology. American Psychologist, 70(1), 33-46. https://doi.org/10.1037/a0038112

American Psychological Association, Board of Educational Affairs. (2014). Guidelines for clinical supervision in health service psychology. Retrieved from http://www.apa.org/about/policy/guidelines-supervision.pdf

Association of State and Provincial Psychology Boards (ASPPB). (2015). Supervision guidelines for education and training leading to licensure as a health service psychologist. Retrieved from www.asppb.net/resource/resmgr/Guidelines/Final_Supervision_Guidelines.pdf

Bang, K., \& Goodyear, R.K. (2014). South Korean supervisees' experience of and response to negative supervision events. Counselling Psychology Quarterly, 27(4), 353-378. https://doi.org/10.1080/0 9515070.2014.940851

Barnett, J.E., \& Molzon, C.H. (2014). Clinical supervision of psychotherapy: Essential ethics issues for supervisors and supervisees. Journal of Clinical Psychology, 70(11), 1051-1061. https://doi.org/10.1002/jclp.22126

Canadian Psychological Association. (2009). Ethical guidelines for supervision in psychology: Teaching, research, practice and administration. Retrieved from: http://www.cpa.ca/docs/file/Ethics/EthicalGuidelinesSupervisionPsychologyMar2012.pdf

Deng, J., Qian, M., Gan, Y., Hu, S., Gao, J., Huang, Z., \& Zhang, L. (2016). Emerging practices of counseling and psychotherapy in China: Ethical dilemmas in dual relationships. Ethics and Behavior, 26(1), 63-86. https://doi.org/10.1080/10508422.2014.978978

Ellis, M.V., Berger, L., Hanus, A., Ayala, E.E., Swords, B.A., \& Siembor, M. (2014). Inadequate and harmful clinical supervision: Testing a revised framework and assessing occurrence. The Counseling Psychologist, 42, 434-472. https://doi.org/10.1177/0011000013508656 
Ellis, M.V., Creaner, M., Hutman, H., \& Timulak, L. (2015). A comparative study of clinical supervision in the republic of Ireland and the United States. Journal of Counseling Psychology, 62(4), 621-631. https://doi.org/10.1037/cou0000110

Ellis, M.V., Taylor, E.J., Corp, D.A., Hutman, H., \& Kangos, K.A. (2017). Narratives of harmful clinical supervision: Introduction to the Special Issue. The Clinical Supervisor, 36(1), 4-19. https://doi.org/10.1080/07325223.2017.1297753

European Federation of Psychologists' Associations (2019). Ethical guidelines for psychologists in the role of trainers, supervisors and teachers of psychologists. Personal communication, Nina Dalen, November 19, 2019.

Falender, C.A. (2018). Clinical supervision: The missing ingredient. American Psychologist, 73, 12401250. https://doi.org/10.1037/amp0000385

Falender, C.A., Grus, C., McCutcheon, S., D., Goodyear, R., Ellis, M.V., Doll, B., ... Kaslow, N. (2016). Guidelines for Clinical Supervision in Health Service Psychology: Evidence and implementation strategies. Psychotherapy Bulletin (Division 29), 51(3), 6-18. http://societyforpsychotherapy.org/ guidelines-clinical-supervision-health-service-psychology/

Falender, C.A. \& Shafranske, E. P. (2004). Clinical supervision: A competency-based approach. Washington, DC: American Psychological Association. https://doi.org/10.1037/10806-000

Falender, C.A. \& Shafranske, E.P. (2007). Competence in competency-based supervision practice: Construct and application. Professional Psychology: Research and Practice, 38, 232-240. https://doi.org/10.1007/s10879-011-9198-9

Falender, C.A., \& Shafranske, E.P. (2010). Psychotherapy-based supervision models in an emerging competency-based era: A commentary. Psychotherapy: Theory, Research, Practice, Training, 47, 45-50. https://doi.org/10.1037/a0018873

Falender, C.A. \& Shafranske, E.P. (in press). Clinical supervision: A competency-based approach $\left(2^{\text {nd }}\right.$ ed.). Washington, DC: American Psychological Association.

Gonsalvez, C.J., \& Calvert, F.L. (2014). Competency-based models of supervision: Principles and applications, promises and challenges. Australian Psychologist, 49, 200-208. https://doi.org/10.1111/ap.12055

Gottlieb, M.C., Robinson, K., \& Younggren, J.N. (2007). Multiple relations in supervision: Guidance for administrators, supervisors, and students. Professional Psychology: Research and Practice, 38, 241-247. https://doi.org/10.1037/0735-7028.38.3.241

Hendricks, S., \& Cartwright, D.J. (2018). A cross-sectional survey of South African psychology interns' perceptions of negative supervision events. South African Journal of Psychology, 48, 86-98. https://doi.org/10.1177/0081246317698858

International Union of Psychological Science (2008). International declaration of ethical principles for psychologists. Retrieved from: https://www.iupsys.net/about/governance/universal-declarationof-ethical-principles-for-psychologists.html

Ladany, N., Hill, C.E., Corbett, M.M., \& Nutt, E.A. (1996). Nature, extent and importance of what psychotherapy trainees do not disclose to their supervisors. Journal of Counseling Psychology, 43(1), 10-24. https://doi.org/10.1037/0022-0167.43.1.10

Ladany, N., Lehrman-Waterman, D., Molinaro, M., \& Wolgast, B. (1999). Psychotherapy supervisor ethical practices: Adherence to guidelines, the supervisory working alliance, and supervisee satisfaction. The Counseling Psychologist, 27(3), 443-475. https://doi.org/10.1177/0011000099273008

Ladany, N., Mori, Y., \& Mehr, K.W. (2013). Effective and ineffective supervision. The Counseling Psychologist, 41(1), 28-47. https://doi.org/10.1177/0011000012442648

Leach, M., \& Harbin, J. (1997). Psychological ethics codes: A comparison of 24 countries. International Journal of Psychology, 32, 181-192. https://doi.org/10.1080/002075997400854

Liu, B.C.C. \& Vaughn, B.S. (2019). Legal and policy issues from the United States and internationally about mandatory reporting of child abuse. International Journal of Law and Psychiatry, 64, 214-224. https://doi.org/10.1016/j.ijlp.2019.03.007

Lovell, C. (2007). Supervisee experiences of poor and harmful clinical supervision (unpublished doctoral dissertation). Melbourne, Australia: Swinburne University of Technology. Retrieved from https://researchbank.swinburne.edu.au/file/476c3312-bd68-4de5-b5d5-494d814b39f6/1/Colleen\%20Lovell\%20Thesis.pdf 
Neimeyer, G.J., Taylor, J.M., Rozensky, R.H., \& Cox, D.R. (2014). The diminishing durability of knowledge in professional psychology: A second look at specializations. Professional Psychology: Research and Practice, 45(2), 92-98. https://doi.org/10.1037/a0036176

New Zealand Psychologists Board. (2007). Guidelines on supervision. Retrieved from: http://www. psychologistsboard.org.nz/cms_show_download.php?id=220

Orlinsky, D.E., Ronnestad, M.H., \& the Collaborative Research Network of the Society for Psychotherapy Research. (2005). How psychotherapists develop: A study of therapeutic work and professional growth. Washington, DC:American Psychological Association.https://doi.org/10.1037/11157-000

Pettifor, J.L., McCarron, M.C.E., Schoepp, G., Stark, C., \& Stewart, D. (2011). Ethical supervision in teaching, research, practice, and administration. Canadian Psychology, 52, 198-205. https://doi.org/10.1037/a0024549

Pettifor, J. \& Ferrerro, A. (2012). Ethical dilemmas, cultural differences and the globalization of psychology. In M.L. Leach, M.J. Stevens, G. Lindsay, A. Ferreo, \& Y. Korkut (Eds.), The Oxford Handbook of International Psychological Ethics (pp. 28-41). New York: Oxford University Press. https://doi.org/10.1093/oxfordhb/9780199739165.013.0003

Pettifor, J., Sinclair, C., \& Falender, C,A, (2014). Ethical supervision: Harmonizing rules and ideals in a globalizing world. Training and Education in Professional Psychology, 8(2), 1-10. https://doi.org/10.1037/tep0000046

Psychology Board of Australia. (2013). Guidelines for supervisors and supervisión training providers. Retrieved from Psychology Board of Australia website: http://www.psychologyboard.gov.au/Standards-and-Guidelines/Codes-Guidelines-Policies.aspx

Rings, J.A., Genuchi, M.C., Hall, M.D., Angelo, M., \& Cornish, J.A.E. (2009). Is there consensus among predoctoral internship training directors regarding clinical supervision competencies? A descriptive analysis. Training and Education in Professional Psychology, 3, 140-147. https://doi.org/10.1037/a0015054

Russian Psychological Society (2012). Code of Ethics. Retrieved from: http://www.psyrus.ru/en/documents/code_ethics.php

Stedman, J.M., Schoenfeld, L.S., \& O’Donnell, L. (2013). An investigation of internship directors' perspectives on the learning objectives required by the commission on accreditation. Training and Education in Professional Psychology, 7(2), 134-138. https://doi.org/10.1037/a0031660

Thomas, J.T. (2014). International ethics for psychotherapy supervisors: Principles, practices, and future directions. In C.E. Watkins \& D.L. Milne (Eds.) The Wiley international handbook of clinical supervision (pp. 131-154). United Kingdom: Wiley. https://doi.org/10.1002/9781118846360.ch6

Wall, A. (2009). Psychology interns' perceptions of supervisor ethical behavior (Order No. 3359934). Retrieved from https://lib.pepperdine.edu/login?url=https://search-proquestcom.lib.pepperdine.edu/docview/305178099? accountid=13159

Watkins, C.E. (2013). On psychotherapy supervision competencies in an international perspective: A short report. International Journal of Psychotherapy, 17, 78-83. Retrieved from http://pepperdine.worldcat.org/title/on-psychotherapy-supervision-competencies-in-an-internationalperspective-a-shortreport/oclc/830011841\&referer=brief_results

Zur, O. (2017). Multiple relationships in psychotherapy and counseling: Unavoidable, common, and mandatory dual relationships in therapy. New York: Routledge. https://doi.org/10.4324/9781315676135

Original manuscript received November 23, 2019

Revised manuscript accepted December 24, 2019

First published online March 01, 2020

To cite this article: Falender, C. (2020). Ethics of Clinical Supervision: An International Lens. Psychology in Russia: State of the Art, 13(1), 42-53. DOI: 10.11621/pir.2020.0105 